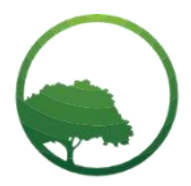

Research in Business \& Social Science

IJRBS VOL 10 NO 5 ISSN: 2147-4478

\title{
Explanatory sequential design of mixed methods research: Phases and challenges
}

Dohammad Abu Sayed Toyon

Department of Management, Estonian Business School, Tallinn, Estonia.

\author{
A R T I C L E IN F O \\ Article history: \\ Received 30 June 2021 \\ Received in rev. form 25 July 2021 \\ Accepted 27 July 2021 \\ Keywords: \\ Explanatory Sequential Design, \\ Mixed Methods Research, Estonia \\ JEL Classification: \\ C18, C80
}

\begin{abstract}
A B S T R A C T
The purpose of this essay is to discuss the phases and challenges of the explanatory sequential design (ESD hereinafter) of mixed methods research (MMR hereinafter) by reviewing relevant literature. The literature was explored during the design stage of a Ph.D. project that sought to examine the relationship among social capital, education, and employment for foreign students graduating from several Estonian universities. The review finds that the explanatory sequential design of MMR is much more complex than just sequencing how and what kind of data to collect; it also entails selecting how data will be processed and presented using a range of techniques that are often riddled with difficulties. By addressing these ideas, this paper will aid those interested in comprehending the summary of the explanatory sequential design of MMR.
\end{abstract}

(C) 2021 by the authors. Licensee SSBFNET, Istanbul, Turkey. This article is an open access article distributed under the terms and conditions of the Creative Commons Attribution (CC BY) license (http://creativecommons.org/licenses/by/4.0/).

\section{Introduction}

For many decades, social science research has evolved by integrating quantitative and qualitative methods and their associated designs (Teddlie \& Tashakkori, 2009; Ivankova \& Stick, 2006). While previous researchers (Ivankova \& Stick, 2006) have shown how explanatory sequential design of MMR may be utilized in practice, the phases of explanatory sequential design of MMR still need to be discussed.

Due to the fact that ESD of MMR encompasses a range of methodological traditions and approaches; they differ in terms of the data collection techniques utilized, the way data are processed and analyzed, and the manner in which conclusions are generated and validated. Without an understanding of the phases, it seems to offer less to the advancement of research and awareness about the challenges at hand, and may result in the discovery of paradoxes and contradictions.

The aim of this paper is not to evaluate or criticize prior literature on ESD, but to synthesize some of them for new researchers in order to provide a concise overview of the phases of explanatory sequential design of MMR. The sources cited in this essay were explored during the first year of author's doctoral studies. Thus, this paper seems to aid in the comprehension of ESD and associated difficulties that a novice researcher may face while planning explanatory sequential design of MMR.

The rest of the paper can be divided into three sections; the first section provides brief concept of explanatory sequential design, the second section covers the steps involved in ESD, while the third section addresses the difficulties.

* Corresponding author. ORCID ID: 0000-0002-3522-1861

(C) 2021 by the authors. Hosting by SSBFNET. Peer review under responsibility of Center for Strategic Studies in Business and Finance.

https://doi.org/10.20525/ijrbs.v10i5.1262 


\section{Theoretical and Conceptual Background}

\section{Explanatory sequential design}

According to researchers (e.g., Creswell \& Clark, 2017) there are two types of sequential designs of mixed methods research. The first is exploratory sequential design, and the second is explanatory sequential design. This paper particularly focuses on the explanatory sequential design of mixed methods research. The explanatory sequential design of MMR emphasizes the quantitative phase, followed by the qualitative phase (Creswell, 2011). The purpose of the second qualitative phase is often to explain the results discovered in the first quantitative phase, and sometimes to explain outliers that are not entirely consistent with the collected data. Since the analysis of qualitative data is used to explain the quantitative phase's results, thus the term 'explanatory'. Researchers often choose this design if they are quantitatively oriented and comfortable doing research in this manner.

\section{Phases of explanatory sequential design}

The explanatory sequential design depicted in Figure 1 entails several phases, including setting up ontological and epistemological position, establishing an approach to inquiry, collecting data, analyzing quantitative data, recollecting data, analyzing qualitative data, and integrating and reporting the results.

\section{Setting ontological and epistemological position}

Researchers often work within the realm of paradigms (see e.g., Kuhn, 1970), which provides a broad framework for their worldview. Their general methodology for doing research is predicated on distinct theoretical considerations (Saunders, Lewis, Thornhill, \& Bristow, 2019). Ontology is the initial theoretical concept, and it is concerned with 'reality'. The second is referred to as epistemology, and it is concerned with the nature of 'knowledge' about what exists or is thought to exist. In other words, ontological position concerns reality, whereas epistemological position concerns knowledge about reality (Al-Ababneh, 2020; Crotty, 1998). In general, there are two opposing ontological positions in epistemology of social science research such as objectivism and constructivism (Gray, 2014). Objectivism proposes that researchers see the world experimentally, which implies that reality has an objective existence. On the other hand, constructivism believes that human beings are meaning-making entities and that the integration of such meanings in social life occurs within the cycle of social existence. Indeed, constructivism's ontological premise highlights the social construction of reality (Gray, 2014). In this way, the knowledge created by objectivists differs from that produced by constructivists.

However, positivism and interpretivism are two distinct theoretical perspectives (Crotty, 1998). Knowledge of the research object lets researchers determine what to research, how to research and what design is to work to create and recreate the ultimate knowledge. In a positivist perspective, the only way to get the reality is to 'lab-test-science' what researchers (Kincheloe \& Tobin, 2009) called systematic scientific steps. Positivism's perspective is to undertake systematic, step-by-step attempts to adapt natural science's perspective to social sciences. In essence, positivist scholars believe that there is only objective reality and that the analytical techniques used to find it are concerned with hypothesis, replication, reliability, and generalization (Kincheloe \& Tobin, 2009). In this sense, positivists align themselves with objectivists, who assert that the purpose of research is to experiment on phenomena that can only be observed and quantified, with the exception of knowledge that cannot be directly observed or quantified, such as emotions, feelings, and so on. Interpretivism offers a whole new perspective on this. The interpretivists challenge the positivist premise that there is no one objective reality since the world is fundamentally social and created socially. The world is about people's perceptions of reality and their perceptions of the world as a consequence of their interactions with others and the environment in which those interactions occur. In this view, constructivism and interpretivism are synonymous.

Other theoretical paradigm, for example, critical realism states that there is an observable structure or reality that exists independently of human thought (Baert, 2005). According to critical realists, this structure is what generates the phenomena that surround us, and therefore the social reality can only be understood if people understand the structure (Bhaskar, 2009). This indicates that although there is no direct connection between our experience of reality and our knowledge of it, there is an indirect connection between meaning and representation. Thus, there is something external to us, and our perception of it is filtered via our limited ability. In this way, the realistic ontology establishes its boundaries by suggesting that everything is socially created and beyond our comprehension, but it seems realistic only when empirical (Abdul, 2015).

Pragmatism, as a research philosophy, provides a degree of adaptability in the production of knowledge (Morgan, 2014). Because it recognizes the existence of many different realities, pragmatism's epistemology does not include a single line of inquiry, but multiple ways of inquiry (Lewis, Saunders, \& Adrian, 2009). Pragmatism often rejects the dichotomy between realism and anti-realism that is fundamental to positivist rhetoric and social scientific interpretations (Morgan, 2014). Indeed, pragmatists acknowledge the existence of several realities, but recognize that they are always changing and dependent on our actions and experiences (Kaushik \& Walsh, 2019). The many realities are then comprehended by integrating various perspectives. By integrating empirical analyses with scientific evidences, the pragmatic researcher aims to develop a more complete knowledge of the research issue (Kelly \& Cordeiro, 2020). Thus, the empirical inquiry would contribute to a more holistic perspective of research, ultimately leading to a balanced conclusion. In this sense, pragmatists acknowledge the existence of some established social structures (Bhaskar, 2009), but also acknowledge the involvement of individuals in their formation and development-a highly interpretivist perspective. Therefore, 
pragmatists embrace both interpretivist and positivist views, and by integrating these two viewpoints, pragmatism allows a more complete understanding of research objectives (Creswell, 2009).

Each of the paradigms mentioned before has its own set of advantages and disadvantages. The researcher and the research objective shall decide how much adherence to a rigorous philosophical position is necessary to complete the research work (Taylor, 2018). Due to the fact that being limited and too focused on a particular philosophical perspective may obstruct the study of those areas that may expand their understanding of the field of science, it is recommended that social science research be conducted without regard for rigid philosophical constraints (Kemp, 2005). In terms of philosophical worldviews, different researchers (Creswell \& Clark, 2017) suggest that because explanatory sequential design incorporates two distinct research traditions, researchers may consider adopting two distinct worldviews or a single philosophical position that is appropriate for completing the research task.

\section{Setting approach of inquiry}

Divergent views on social reality create divergent opinions on the logic that underpins the creation of an inquiry. Scientific methodology is the interplay of abduction, which involves the acceptance of explanatory plausibility, induction, which includes the empirical testing of putative inferences, and deduction, which entails deriving implications from accepted inferences (Burks, 1946).

According to previous literature (Park, Bahrudin, \& Han, 2020), the quantitative approach typically follows a deductive logic of inquiry, which entails shifting away from specific facts and toward a generalized theory or abstract scientific ideas; in other words, theory drives the hypothesis of the inquiry. As a thinking process, deduction is a movement from particular provisions to a more general perspective (Saunders, Lewis, Thornhill, \& Bristow, 2019). A researcher uses a deductive method to research when he or she formulates hypotheses and implications based on pre-existing theories about the topic of the study. The methodology for data collection is dictated by theoretical assumptions. Following that, the assumptions are verified or refuted in light of real evidence, thus validating or refuting the theory. On the other hand, inductive reasoning is a method of reasoning from the general to the particular, in which broad conclusions are derived from evidence. Inductive inquiry progresses from evidence to generalizing ideas and finally to theory building.

It should be emphasized, however, that no study can be performed entirely on the basis of deductive or inductive reasoning (Robert, 2019). Inductive reasoning is a component of any deductive inquiry. When testing hypotheses based on collected data, for example, the process of moving from observations to general statements is used, i.e., inductive reasoning is applied. On the other hand, inductive logic-based research often utilizes theory as a springboard, a broad framework for generating research topics. Thus, while developing an explanatory research design, researchers must choose which method of inquiry is appropriate for the investigation's framework

\section{Data collection phase}

The data collecting process begins with the development of instruments for obtaining raw data or the selection of pre-existing databases that are relevant to the study's objectives (Creswell, 2011). The process of instrument creation is influenced by the technique of inquiry chosen. For example, if the data collecting technique is a survey, the development of a questionnaire is a crucial step. Similarly, interviewing is a method for eliciting information from a respondent via the use of a prepared sequence of questions (Saunders, Lewis, Thornhill, \& Bristow, 2019). The sequence, content, and structure of questions, as well as the techniques used to answer them, should all be structurally consistent. In this regard, the questionnaire is comparable to a standardized interview. The questionnaire's quality has a significant effect on the research's reliability (Creswell \& Clark, 2017). A questionnaire may include structured questions as well as open-ended inquiries.

In social science research, surveys are often used to collect quantitative data (Ponto, 2015). Survey method may be classified based on how the interviewer and responder interact or communicate. The responder answers to the questionnaire's questions through mail/e-mail (correspondence survey) or in person (in-person survey/face-to-face survey). Direct contact with respondents through organized interviews is possible, as is indirect connection with respondents via telephone interviews including those using internetassisted technology and systematic questioning via online polls. Additionally, survey techniques may be classified as individual and group, mass and specialized. However, survey techniques are not without their drawbacks. For instance, coverage error, sampling error, non-response error, and measurement error are only a few of the difficulties to consider prior to using the survey method (Ponto, 2015).

\section{Analysis of quantitative data}

As depicted in the Figure 1, data analysis is divided into two stages: quantitative and qualitative. Quantitative data analysis techniques are intended for the examination of measurable features in order to provide quantitative findings. Such analysis entails the processing of data using organized methods that are quantitative in nature. For instance, descriptive analysis entails determining, characterizing and describing the target population. Descriptive analysis and descriptive data are two distinct concepts (see e.g., Nassaji, 2015). Descriptive analysis provides response to the query "what happened?" by summarizing descriptive information and historical data in preparation for future investigation. It analyzes data using statistical techniques such as principal component analysis, cluster analysis and factor analysis to cluster, categorize, and determine the variables affecting the outcomes (Gabor, 2010). It often involves correlation studies, which serve as a breeding ground for hypotheses that may be investigated experimentally in more depth. 
Predictive analysis is a technique that forecasts unknown variables by answering the question "what might happen?" based on the study of collected data (Kumar \& Garg, 2018). Several techniques, such as mathematical statistics and modeling, may be utilized in this case. Prescriptive analysis addresses the question "what to do?" through the use of what-if scenarios. In prescriptive analysis, researchers use techniques to evaluate all gathered and processed data in order to determine the best answers for a given question (Lepenioti, Bousdekis, Apostolou, \& Mentzas, 2020).

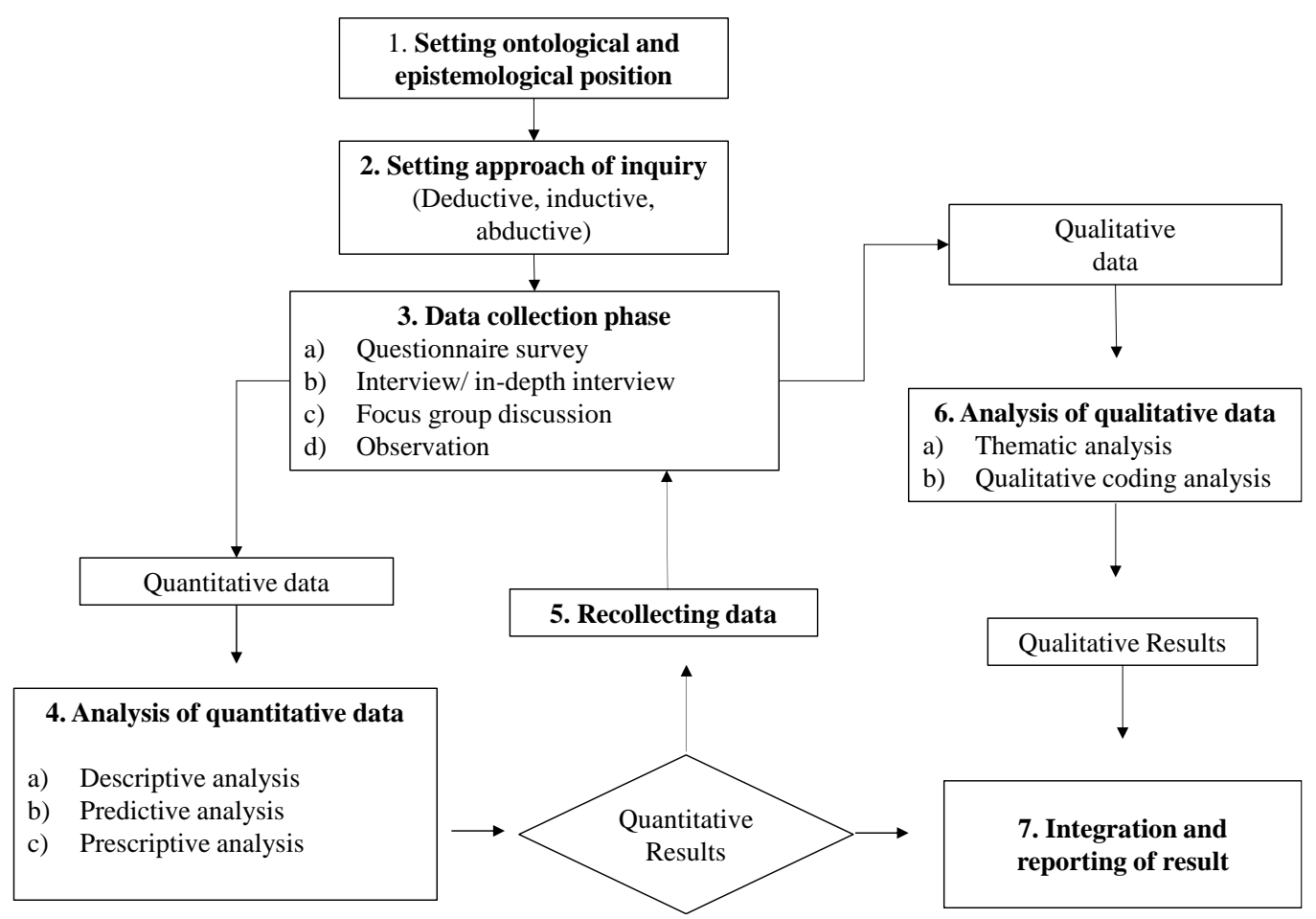

Figure 1: Workflow of Explanatory Sequential Design of MMR (developed by author based on literature)

\section{Recollecting data}

This phase of data gathering is driven by the quantitative result. The data collected during this phase are qualitative (for example, text, video, audio, and image), which determines what techniques should be utilized to acquire data that provides additional insight into the research (Creswell \& Clark, 2017). In-depth interview, focus group discussion and observation are just a few of the methods utilized to gather qualitative data during this phase (Ivankova \& Stick, 2006).

The in-depth interview is a method for extracting essential information via open-ended or organized dialogue between the interviewer and the interviewee. It's worth noting that the word 'in-depth' refers to the connection between the interviewer and responder during the deliberate conversation (Talja, 1999). In-depth interview technique has a number of benefits and drawbacks. In-depth interview approach requires extensive planning and the creation of a certain relationship with the interviewees. Due to the established trust relationship, this technique enables the respondent to provide requested details (Lewis, Saunders, \& Adrian, 2009). As a result of the developed trust connection, the responder is able to give required information. By and large, the information collected is unique and comprehensive, allowing researchers to combine and analyze large amounts of data. This method's peculiarity is manifested in the meticulous preparing and review of all questions for the respondent. The interviewer's preparation, knowledge, and even presentation all contribute to the effectiveness of the in-depth interview. Here, preparation and a sense of proportion are required; it is also necessary to be a very attentive listener. The increased urgency with which in-depth interviews are conducted puts extra resource limitations on both the investigator and the interviewee.

The focus group discussion technique is similar to that of an interview, except that it is conducted in groups rather than individually (Morgan, 1997). A focus group may refer to the research technique itself or, more precisely, to a group of respondents who will take part in the inquiry. The researcher seeks the respondents' subjective or objective views on the topics during the group discussion. The effectiveness of focus group discussions is determined by a variety of factors, including a well-designed (methodologically sound) preparation, participant composition, skilled group moderator, and comfortable location (Dilshad \& Latif, 2013; Morgan, 1997).

Observation is a technique for gathering data that involves monitoring research participants such as people, groups, and so forth (Jamshed, 2014). When a researcher observes, he or she automatically becomes a member of the group under observation. 
Observation does include emic-etic paradoxes. The emic perspective may be described as one in which the researcher takes an insider's perspective (Morey \& Luthans, 1984). Having said that, when a researcher does inquiry on a particular topic, he or she enters the field and tries to understand social phenomena through the eyes of the research participants. This is the opposite in etic terms; in emic views, the researcher takes an insider's perspective, while in etic ones, the researcher adopts an outside observer's perspective. The efficacy of observation is contingent upon the observer's ability to comprehend and adapt to the qualities of study participants; this is especially important for features like tangible culture and language (Smit \& Onwuegbuzie, 2018; Kawulich, 2005).

\section{Analysis of qualitative data}

Qualitative data analysis can be carried out in a number of ways, including coding and thematic analysis. A theme is a descriptive term that refers to the representation and other phenomena observed in the data. It manifests itself when relevant findings are repeated many times in the responses of participants or in the examined sources. The technique of thematic analysis requires some degree of qualitative coding (Guest, MacQueen, \& Namey, 2012). This coding process makes it simpler to locate significant themes (Guest, MacQueen, \& Namey, 2012). Thus, thematic analysis is a technique for categorizing and arranging data that involves assigning unique codes to each observation and quotation. Indeed, coding is the process of deconstructing, comparing, understanding, and categorizing data. It is the process of generating a list of concepts or themes that best describe a collection of information. The code denotes the text's topic and serves as a shorthand for a broader concept or theme (Linneberg \& Korsgaard, 2019). For instance, code might be used to describe a narrative in the same way that a keyword defines an article or a hashtag identifies a social media post. However, the coding process may be classified as deductive or inductive (Linneberg \& Korsgaard, 2019). Deductive coding is a qualitative coding strategy in which researchers begin with a set of preset codes and then seek for extracts that match those codes, while inductive coding is another strategy in which researchers begin with no codes and create them as they examine the dataset.

\section{Integration and reporting of result}

There are many recommendations (see e.g., Creswell \& Tashakkori, 2007) available for how researchers that embrace MMR will publish their manuscripts. It is possible to evaluate and contrast the quantitative and qualitative findings; it is also conceivable to mix them and just explain how their respective conclusions could be extended (Creswell \& Tashakkori, 2007). Another researcher (Bryman, 2007) proposed that depending on the goals and barriers, the report may be presented sequentially or combined. Indeed, the manner in which the findings are conveyed will depend on a number of factors including the importance of time lines, different audiences, and publishing constraints (Bryman, 2007). The project's timeline may demand the findings to be published within a certain timeframe. Another aspect to consider is the intended audience for the study, which may necessitate publishing the quantitative and qualitative results sequentially. Finally, researchers may also have the option of integrating their findings, which means that reports may be prepared in conjunction with one another.

\section{Difficulties in adopting the explanatory sequential design}

When addressing the difficulties associated with the explanatory sequential design of MMR, it's crucial to understand that ESD incorporates both quantitative and qualitative research traditions. Thus, ESD is confronted with the same challenges as these two research traditions. Due of the many phases involved in the explanatory sequential design, it poses a variety of challenges, including but not limited to the following: complexity in the inquiry (Guest, 2013; Morse \& Niehaus, 2009), sampling issue (Creswell \& Clark, 2017) and a longer timescale (Doyle, Brady, \& Byrne, 2016). To address all of these issues, it seems feasible to bring up the concepts of reliability and validity. The key to validity and reliability is to use appropriate research method that correctly identifies, evaluates, and analyzes the research topic.

Reliability in quantitative research tradition is contingent upon the findings being repeated and reproducible (Lewis, Saunders, \& Adrian, 2009) and this refers to the instrument used to gather data, the design and the approach utilized in the inquiry. A more reliable instrument can translate into a more credible research project. When quantitative data are gathered through a questionnaire instrument, a variety of reliability tests may be used to ascertain the instrument's reliability. Among these are the test-retest method, the parallel forms method, the split-halves approach, and the internal consistency approach (Middleton, 2019). Several researchers (Creswell \& Clark, 2017; Abowitz \& Toole, 2010; Onwuegbuzie \& Collins, 2007) have also discussed various approaches to address the issue of reliability including maintaining the representativeness of sample. Representativeness refers to a sample's ability to replicate the fundamental characteristics of the broader population (Merom \& John, 2019). There are many methods for ensuring representativeness of sample. For instance, random sampling, quota sampling, and purposeful sampling (Saunders, Lewis, Thornhill, \& Bristow, 2019; Creswell \& Clark, 2017).

By ensuring a representativeness of sample, researchers also address the issue of validity. Face validity, content validity, criteria validity, and construct validity are some of the validity tests (Merom \& John, 2019). These are used to determine if an instrument is measuring what it is supposed to be measuring. The validity of a data collection instrument (questionnaire), is defined by its ability to accurately quantify desirable characteristics of the object. In fact, adhering to this criterion ensures the internal validity of the research (Abowitz \& Toole, 2010). Researchers (Saunders, Lewis, Thornhill, \& Bristow, 2019; Creswell \& Clark, 2017) propose that in order to develop a robust data collecting instrument, various methods can be used, including a comparison of instruments developed using existing methodology in the relevant area and consulting with experts in the subject. It is also critical to recall that 
the stability of information is defined by its capacity to remain unambiguous, that is, identical when received in a variety of contexts. Such quality of information is often referred to as credibility (Korstjens \& Moser, 2018), and it may be confirmed via repeated measurements, several witnesses seeing the same characteristic, and splitting the scale or examining the scale in segments.

While reliability is often used to refer to the consistency and repeatability of results in quantitative analytical frameworks, it does not always applicable to qualitative analysis using observations and interviews as measuring instruments (Lincoln, 1995). This is because whenever researcher measures anything for the second time, it is always a new object (Eriksson \& Kovalainen, 2008). In this case, the researcher uses confirmability as a proxy for reliability. Confirmability is a qualitative term that refers to the degree to which the results of a qualitative investigation can be confirmed by other researchers. Indeed, qualitative data must satisfy the requirements of confirmability, plausibility, and transferability (Eriksson \& Kovalainen, 2008; Lincoln, 1995). The parameter confirmability is similar to the standard data robustness criterion for determining the reliability of a research instrument. In qualitative tradition the researcher is regarded as the instrument (Lincoln, 1995). Lincoln (1995) explores the notion of believability in place of internal validity. Because the objective of qualitative research is to explain and comprehend phenomena through the eyes of the participants, they are the only ones who can assess the findings' plausibility (Eriksson \& Kovalainen, 2008). Credibility (plausibility) refers to the degree to which the results of a qualitative investigation are trustworthy from the viewpoint of the research participants. External validity is related to transferability, which is the extent to which the results may be generalized (Eriksson \& Kovalainen, 2008).

Reliability and validity are critical challenges in any research, and ESD of MMR is no exception. It is essential to understand how to approach issues of reliability and validity from both quantitative and qualitative viewpoints. Due to the involvement of these two distinct research traditions, quantitative and qualitative, ESD of MMR needs more vigilance throughout the process to guarantee that generated findings are consistent. Perfection in terms of reliability and validity is almost difficult to attain. Nevertheless, researchers can maximize the reliability and validity of their research by sticking to the compliances that contribute to the value of the results. However, the value of research is not only decided by its reliability and validity. The legitimacy of the study dictates its broad practical use, and it is via this that researchers obtain trustworthy findings (Onwuegbuzie \& Johnson, 2006).

\section{Conclusion}

Explanatory sequential design of mixed methods research incorporates both quantitative and qualitative research tradition. Neither technique is superior to the other; rather, each has its own set of benefits and drawbacks and is intended to ease the completion of a specific set of research tasks. While both qualitative and quantitative techniques employs a variety of methods for collecting data, including survey, interviews, in-depth interviews, focus group discussion and observation, their analytical framework is distinct. The distinction between qualitative and quantitative method is that qualitative techniques are not concerned with statistical evaluations and measurements, but with the comprehension and interpretation of empirical facts. They are often characterized by a focus on inductive reasoning, propositions, theory development, and the integration of social constructionism, and they offer answers to the 'how' and 'why' questions. But quantitative technique involves the strategies of collecting and analyzing quantitative data. It is useful for identifying trends and averages, making forecasts, examining causal relationships which often provides an answer to the 'what' inquiry. The researchers utilize positivist and post-positivist philosophy to develop knowledge in quantitative approach, which includes deduction, confirmation of hypotheses and testing theories, among other things, using descriptive, experimental, or quasiexperimental research strategies. Furthermore, quantitative analytical frameworks are often predicated on predefined survey instruments that serve as the foundation for statistical and mathematical analysis of the research findings. Given the importance of these two research traditions in the ESD of MMR, it is essential to understand and explain the reason for selecting which data should be collected and how they should be acquired in order to adequately answer the research question. However, the difficulties inherent in the ESD of MMR begin with the formulation of the research question, the establishment of a suitable technique and method of inquiry, the development of a data analysis framework, and the presentation of results. Objectivity, reliability, internal validity, and external validity are traditional quantitative evaluation criteria; alternatively, qualitative evaluation criteria includes confirmability, plausibility and transferability. Several strategies can be followed for overcoming the challenges, for example, conducting a review of the existing literature on research methods, explicitly defining theoretical concepts before they can be quantified and operationalized in a valid and reliable manner, planning an inquiry to ensure successful data collection and selecting an appropriate analytical technique for producing meaningful and acceptable results.

This essay has reviewed a small number of articles and addressed the stages and difficulties associated with designing the ESD for mixed method research. The utilization of ESD is especially pertinent in fields of study where it is critical to establish a research framework through the integration of quantitative and qualitative research traditions. This paper is important in a sense that the discussion in this paper on explanatory sequential design of mixed methods research is the tip of the iceberg and should serve as a primer for novice researchers. The scope of future research is open to elucidate the difficulties inherent in aligning quantitative and qualitative results, and whether qualitative findings always complement quantitative findings.

\section{References}

Abdul, A. (2015). The Central Arguments of Critical Realism and Positivism Approaches and an Evaluation of Their Impact upon a Proposed Research Project. International Journal of Current Research, 7(12), 23867 -23870. 
Abowitz, D. A., \& Toole, T. M. (2010). Mixed Method Research: Fundamental Issues of Design, Validity, and Reliability in Construction Research. Journal of Construction Engineering and Management, 136(1), 108-116. https://doi.org/10.1061/(ASCE)CO.1943-7862.0000026

Al-Ababneh, M. M. (2020). Linking Ontology, Epistemology and Research Methodology. Science \& Philosophy, 8(1), 75-91. https://ssrn.com/abstract=3708935

Baert, P. (2005). Critical Realism. In P. Baert, Philosophy of the Social Sciences: Towards Pragmatism (pp. 87-105). UK: Polity Press.

Bhaskar, R. (2009). Scientific Realism and Human Emancipation. London, UK: Routledge. https://doi.org/10.4324/9780203879849

Bryman, A. (2007). Barriers to Integrating Quantitative and Qualitative Research. Journal of Mixed Methods Research, 1, 8-22. https://doi.org/10.1177/1558689806290531

Burks, A. W. (1946). Peirce's Theory of Abduction. Philosophy of Science, 13(4), 301-306. https://doi.org/10.1086/286904

Creswell, J. (2009). Research Design: Qualitative, Quantitative, and Mixed Methods Approaches. UK: SAGE Publications Ltd.

Creswell, J. (2011). Planning, Conducting, and Evaluating Quantitative and Qualitative Research. New York: Pearson.

Creswell, J., \& Clark, V. (2017). Designing and Conducting Mixed Methods Research (3rd ed.). London: SAGE.

Creswell, J., \& Tashakkori, A. (2007). Editorial: Developing Publishable Mixed Methods Manuscripts. Journal of Mixed Methods Research, 106-111. https://doi.org/10.1177/1558689806298644

Crotty, M. (1998). The Foundations of Social Research: Meaning and Perspective in the Research Process. London: SAGE.

Dilshad, R. M., \& Latif, M. I. (2013). Focus Group Interview as a Tool for Qualitative Research: An Analysis. Pakistan Journal of Social Sciences (PJSS), 33(1), 191-198.

Doyle, L., Brady, A. M., \& Byrne, G. (2016). An Overview of Mixed Methods Research - Revisited. Journal of Research in Nursing, 21(8), 623-635. https://doi.org/10.1177/1744987116674257

Eriksson, P., \& Kovalainen, A. (2008). Qualitative Research Evaluation. In P. Eriksson, \& A. Kovalainen, Qualitative Methods in Business Research (pp. 290-297). CA: SAGE. https://doi.org/10.4135/9780857028044

Gabor, M. R. (2010). Descriptive Methods of Data Analysis for Marketing Data-Theoretical and Practical Considerations. Management and Marketing, 5(3), 119-134.

Gray, D. E. (2014). Doing Research in the Real World. Washington DC: SAGE publication.

Guest, G. (2013). Describing mixed methods research: An alternative to typologies. Journal of Mixed Methods Research, 141-151. https://doi.org/10.1177/1558689812461179

Guest, G., MacQueen, K. M., \& Namey, E. E. (2012). Applied Thematic Analysis. Los Angeles: SAGE. https://doi.org/10.4135/9781483384436

Ivankova, N. V., \& Stick, S. L. (2006). Students' Persistence in a Distributed Doctoral Program in Educational Leadership in Higher Education: A Mixed Methods Study. Research in Higher Education, 48(1), 93-135. https://doi.org/10.1007/s11162-0069025-4

Jamshed, S. (2014). Qualitative Research Method-Interviewing and Observation. Journal of Basic and Clinical Pharmacy, 5(4), 8788. https://doi.org/10.4103/0976-0105.141942

Kaushik, V., \& Walsh, C. A. (2019). Pragmatism as a Research Paradigm and Its Implications for Social Work Research. Social Sciences, 8(9), 1-17. https://doi.org/10.3390/socsci8090255

Kawulich, B. B. (2005). Participant Observation as a Data Collection Method. Forum qualitative social research, 6(2), Article 43. http://nbn-resolving.de/urn:nbn:de:0114-fqs0502430

Kelly, L. M., \& Cordeiro, M. (2020). Three Principles of Pragmatism for Research on Organizational Processes. Methodological Innovations, 13(2), 1-10. https://doi.org/10.1177/2059799120937242

Kemp, S. (2005). Critical Realism and the Limits of Philosophy. European Journal of Social Theory, 8(2), 171-191. https://doi.org/10.1177/1368431005051762

Kincheloe, J. L., \& Tobin, K. (2009). The Much Exaggerated Death of Positivism. Cultural Studies of Science Education, 4, 513528. https://doi.org/10.1007/s11422-009-9178-5

Korstjens, I., \& Moser, A. (2018). Series: Practical Guidance to Qualitative Research, Part 4: Trustworthiness and Publishing. European Journal of General Practice, 24(1), 120-124. https://doi.org/10.1080/13814788.2017.1375092

Kuhn, T. S. (1970). The Structure of Scientific Revolutions. Chicago: University of Chicago Press.

Kumar, V., \& Garg, M. L. (2018). Predictive Analytics: A Review of Trends and Techniques. International Journal of Computer Applications, 31-37. https://doi.org/10.5120/ijca2018917434

Lepenioti, K., Bousdekis, A., Apostolou, D., \& Mentzas, G. (2020). Prescriptive Analytics: Literature Review and Research Challenges. International Journal of Information Management, 57-70. https://doi.org/10.1016/j.ijinfomgt.2019.04.003

Lewis, M., Saunders, P., \& Adrian, T. (2009). Research Methods for Business Students. Essex: Pearson.

Lincoln, Y. S. (1995). Emerging Criteria for Quality in Qualitative and Interpretive Research. Qualitative Inquiry, 1(3), $275-289$. https://doi.org/10.1177/107780049500100301

Linneberg, M. S., \& Korsgaard, S. (2019). Coding Qualitative Data: A Synthesis Guiding the Novice. Qualitative Research Journal, 19(3), 259-270. https://doi.org/10.1108/QRJ-12-2018-0012 
Merom, D., \& John, J. R. (2019). Measurement Issues in Quantitative Research. Handbook of Research Methods in Health Social Sciences, 663-679. https://doi.org/10.1007/978-981-10-5251-4_95

Middleton, F. (2019, August 08). Types of Reliability and How to Measure Them. Retrieved from www.scribbr.com/methodology/types-of-reliability [Accessed 20 February 2021]

Morey, N. C., \& Luthans, F. (1984). An Emic Perspective and Ethno-science Methods for Organizational Research. The Academy of Management Review, 9(1), 27-36. https://doi.org/10.5465/amr.1984.4277836

Morgan, D. L. (1997). Focus Groups as Qualitative Research. Newbury Park: Sage Publications, Thousand Oaks. https://doi.org/10.4135/9781412984287

Morgan, D. L. (2014). Integrating Qualitative and Quantitative Methods: A Pragmatic Approach. Thousand Oaks CA: SAGE Publications. https://doi.org/10.4135/9781544304533

Morse, J. M., \& Niehaus, L. (2009). Mixed Method Design: Principles And Procedures. London: Routledge.

Nassaji, H. (2015). Qualitative and descriptive research: Data Type Versus Data Analysis. Language Teaching Research, 19(2), 129132. https://doi.org/10.1177/1362168815572747

Onwuegbuzie, A. J., \& Collins, K. M. (2007). A Typology of Mixed Methods Sampling Designs in Social Science Research. The Qualitative Report, 12(2), 281-316.

Onwuegbuzie, A., \& Johnson, R. (2006). The validity issue in mixed research. In V. L. Clark, \& J. W. Creswell, The Mixed Methods Reader (pp. 273-298). California: Thousand Oaks, SAGE.

Park, D., Bahrudin, F. I., \& Han, J. (2020). Circular Reasoning for the Evolution of Research through a Strategic Construction of Research Methodologies. International Journal of Quantitative and Qualitative Research Methods, 8(3), 1-23. https://doi.org/10.1007/s11135-020-00969-9

Ponto, J. (2015). Understanding and Evaluating Survey Research. Journal of Advance Practitioner in Oncology, 6(2), $168-171$. https://doi.org/10.6004/jadpro.2015.6.2.9

Robert, D. (2019, Feb 12). Is survey Research Based on Inductive or Deductive Reasoning? Retrieved from https://www.researchgate.net/post/Is-survey-research-based-on-inductive-or-deductivereasoning/5c620fbc661123047b2f1feb/citation/download [Accessed 24 January 2021]

Saunders, M. N., Lewis, P., Thornhill, A., \& Bristow, A. (2019). Research Methods for Business Students (8th ed.). UK: Pearson.

Smit, B., \& Onwuegbuzie, A. J. (2018). Observations in Qualitative Inquiry: When What You See Is Not What You See. International Journal of Qualitative Methods, 17(1), 1-3. https://doi.org/10.1177/1609406918816766

Talja, S. (1999). Analyzing Qualitative Interview Data: The Discourse Analytic Method. Library \& Information Science Research, 21(4), 459-477. https://doi.org/10.1016/S0740-8188(99)00024-9

Taylor, S. P. (2018). Critical Realism Vs Social Constructionism \& Social Constructivism: Application to a Social Housing Research Study. International Journal of Sciences: Basic and Applied Research, 37(2), 216-222.

Teddlie, C., \& Tashakkori, A. (2009). Foundations of Mixed Methods Research: Integrating Quantitative and Qualitative Approaches in the Social and Behavioral Sciences. Los Angeles: SAGE.

Publisher's Note: SSBFNET stays neutral with regard to jurisdictional claims in published maps and institutional affiliations.

\section{(a) (1)}

(C) 2021 by the authors. Licensee SSBFNET, Istanbul, Turkey. This article is an open access article distributed under the terms and conditions of the Creative Commons Attribution (CC BY) license (http://creativecommons.org/licenses/by/4.0/).

International Journal of Research in Business and Social Science (2147-4478) by SSBFNET is licensed under a Creative Commons Attribution 4.0 International License. 